\title{
O Mal-Estar do Desejo: \\ Gosto e Conteúdo na Arte
}

Igor Alexandre Capelatto ${ }^{7}$

DOI 10.20396/eha.vil4.3466

Uma ponte sobre o abismo do desejo

Há uma estreita relação entre o saber e o sentir, e entre o prazer e o conhecimento. Nós, seres humanos, somos efeitos do desejo: desejados e desejantes. Oímpeto que nos move, nos dá diretriz e pulsão de vida é o desejo. É o querer algo, mas algo que possamos não só almejar, mas que possamos identificar (fruição), interagir (pertencer) ou nos tornarmos a coisa (transferência). E, o desejo move-se pelo prazer, mas também pelo desprazer. Todo prazer atinge um clímax de satisfação, estase, que tem duração curta, é um instante de prazer que em pouco tempo se desfaz. Por isso, as pessoas, para suprir a falta do prazer, buscam constante prazeres: o que se torna vício. Esse regozijo, muitas vezes, é ligado a uma fuga daquilo que causa desprazer. O conhecimento por exigir estudo, disciplina, constância de exercício cerebral, acaba sendo associado ao desprazer, portanto, aquilo que nos entretém acaba sendo, na maioria das vezes, o escape do conhecimento (quantas vezes não nos pegamos pensando: 'vou me divertir para descansar de tanto estudar'?). Essa frágil ponte entre prazer e conhecimento se estabelece nessa complicada atitude mental chamada desejo, conferenos uma necessidade de vivenciar o que nos figura como desagrado (ou seja, o desprazer), para atingir algo que nos dê prazer (por exemplo, trabalhar intensivamente, para poder comprar o carro desejado, a casa desejada, fazer a viagem tão sonhada).

Tornamos as coisas prazerosas, ganham potência de um signo, que por mais que contenha conteúdo (história, informação, conhecimento), está na esfera do prazer; agrada² ao olhar, ao tato, ao paladar, ao olfato e à audição; nos causa bem-estar. É a música que nos relaxa, o filme que nos distrai, é a pintura que agrada o olhar na sala de estar, etc. Somos potencializadores de prazer e, portanto, desassociamos o funcional das coisas para as quais foram designadas e atribuímos novas aplicabilidades, por vez, destinadas ao nosso contentamento. Circunstâncias essas que confrontam o emprego primeiro das coisas, com a função estética e com as atribuições poéticas e conceituais a

1 Doutor pela Unicamp, departamento de Multimeios.

2 A função estética dos produtos é o aspecto psicológico da percepção sensorial durante o uso (LÖBACH, 2001, p.58) 
elas outorgadas. Uma das potências maiores que se encontram neste campo é a Obra de Arte. Muitos autores confrontam-se com a árdua tentativa de responder o que é uma obra de arte; e muitas são as possibilidades de formulação de um pensamento acerca da arte, contudo, podemos tomar como uma diretriz, dentro do encadeamento do desejo, a ideia de que as linguagens, signos e objetos ganham um status de arte, no sentido de que, deixam de ser apenas objetos do prazer, e passam a envolver conceitos, pensamentos, reflexões e dúvidas.

Obras de Artes são signos de nossa condição humana, que comunicam nossos sentimentos, nossos desejos, nossas histórias. As obras de arte nascem de uma necessidade humana de conjecturar as coisas humanas (objetos, sentimentos, corpo, gestos e linguagem) em algo com status 'superior' à sua função técnica (uma cadeira deixa de ser um objeto para sentar e se torna um objeto de design, um objeto de museu; a escrita dos povos primitivos feitas por meio de representações icônicas transformadas em arte rupestre; e assim por diante). Neste cenário do desejo, como a arte se situa na relação forma e conteúdo? Uma situação um tanto comum que vemos em nossa sociedade contemporânea é uma contínua permanência de um signo que simula a obra de arte: no museu, na galeria de arte, no teatro, no conservatório, apreciamos a obra original, deleitamos com sua beleza. O prazer atinge os sentidos e nos transporta a um certo 'nirvana' (claro que, cada pessoa, se identificará com um 'tipo' de obra). Mas saímos do espaço artístico e a obra ficou lá, o prazer de estar diante da obra fica retido - o regozijo finda - e, precisamos superar esse desprazer de não ter mais aquele momento. Inventamos então produtos que nos permitem 'levar' a obra para casa: um dvd com as músicas da orquestra, um calendário, um imã de geladeira, uma blusa ou sacola com os quadros que vimos no museu, uma réplica de uma escultura, enfim, inúmeros objetos que 'reproduzem' a 'imagem' da obra.

O esgotamento do prazer é algo que nós, seres humanos, temos tribulação em conviver com; e, mesmo os objetos extensores da obra, não dão conta de perpetuar o prazer, e aligeiramos em busca de outro objeto de prazer. No entanto, desejo não é uma satisfação (essa é mediada pelo prazer), mas uma necessidade humana de "completar o que está incompleto"3. Lacan 4 vai dizer que o sujeito projeta no objeto uma carência, de modo que esse objeto passa a simbolizar não mais a sua função a qual foi originalmente designado, entretanto uma função que o sujeito a determina (representação afetiva). 'Inventamos' as coisas, uma função que nos agrade, que dê conta de ocupar 
o espaço daquilo que não temos. As obras de arte, acabam deferindo essas projeções, e passamos a referencia-las não mais pelo que supostamente se designa pelos próprios artistas, críticos, curadores, pesquisadores acadêmicos, mas por aquilo que torna a obra pessoal, íntima e dá conta de superar nossas carências. Todavia, nesse processo, acontece um fator instigante: obras de arte adquirem memórias outras, ou seja, novas representações. Quantas vezes uma música, uma pintura, um filme etc., não nos fazem lembrar de um momento de nossa vida, de alguém, de um lugar?

\section{A retórica do desejo}

Este panorama do desejo vai nos permitir compreender algumas funções que atribuímos as obras de arte para, assim, tentarmos propor um pensamento reflexivo sobre o conceito de obra de arte e como configura-se a ponte entre o conteúdo e a forma na arte, desvelando uma possível teoria sobre o que é gosto nas artes ${ }^{5}$. Quando o sujeito observa uma obra de arte e cria uma afinidade com ela, o desejo é transferido a obra tornando-se referencial de analogia simbólica do próprio desejo. Três instâncias são observadas: a. quando o sujeito encontra na forma, algo que lhe atinge pelos sentidos e provoca: o sorriso da Monalisa de Da Vinci (figura 1), a ferida pelas flechas em São Sebastião de Rubens (figura 2); b. quando o sujeito encontra algo no conteúdo (na narrativa, no contexto) da obra de arte com o qual ele se identifica: a desconstrução da linguagem em Flores do Mal de Baudelaire ou em A Fonte de Duchamp (Figura $3^{6}$ ); c. quando o sujeito transfere para a obra uma relação com um fato externo a obra (Monalisa não representa Da Vinci ou uma obra Renascentista, mas passa a representar o dia que o sujeito esteve em Paris, a lua de mel, o nascimento de um filho, a celebração de um aniversário, a morte de um ente querido).

\section{SPLEEN (BAUDELAIRE, poema LXXVII, 2018)}

Sou como um rei sombrio de um país chuvoso,

Rico, mas incapaz, moço e, no entanto, idoso,

Que, desprezando do vassalo a cortesia,

Entre seus cães e outros bichos se entedia.

Nada o pode alegrar, nem caça, nem falcão,

Nem seu povo a morrer defronte do balcão.

Do jogral favorito a estrofe irreverente

\footnotetext{
5 Por vez, dialogar sobre o que poderia ser, então, entendido como o 'belo' e o 'feio' nas artes.

6 A figura 3 em comparação com a figura 4 nos mostram um outro aspecto da desconstrução, quando o objeto ressignificado é apresentado junto ao desenho arquitetônico do objeto em si (o manual de confecção do produto).
} 


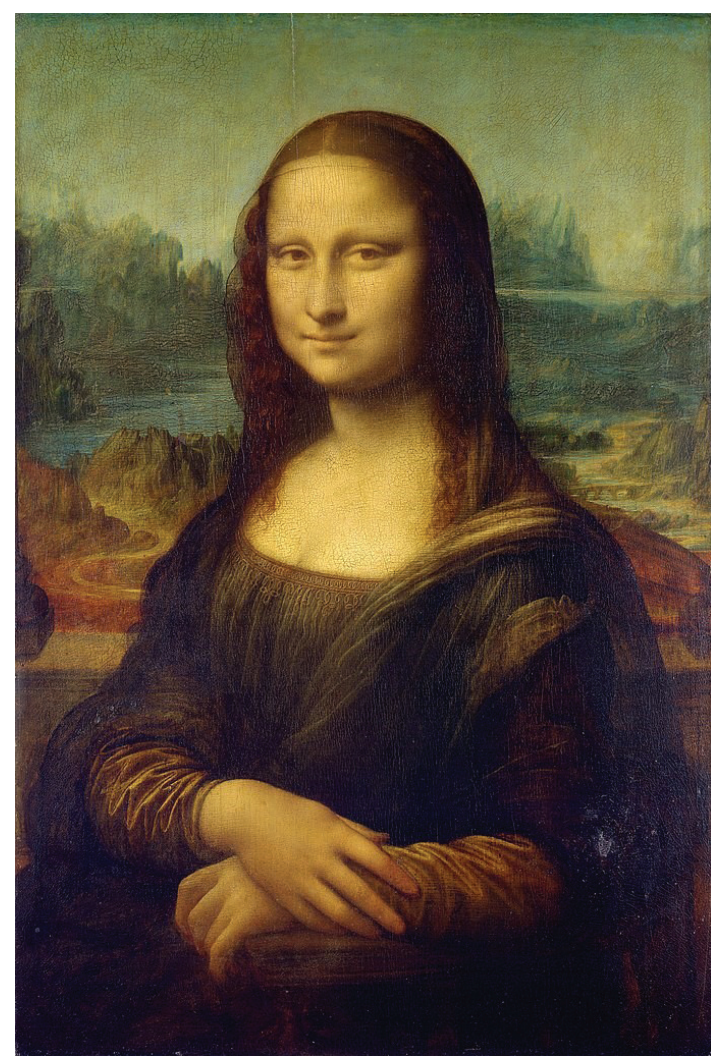

[Figura 1] Leonardo Da Vinci. Monalisa. 1517. Museu do Louvre, Paris, França

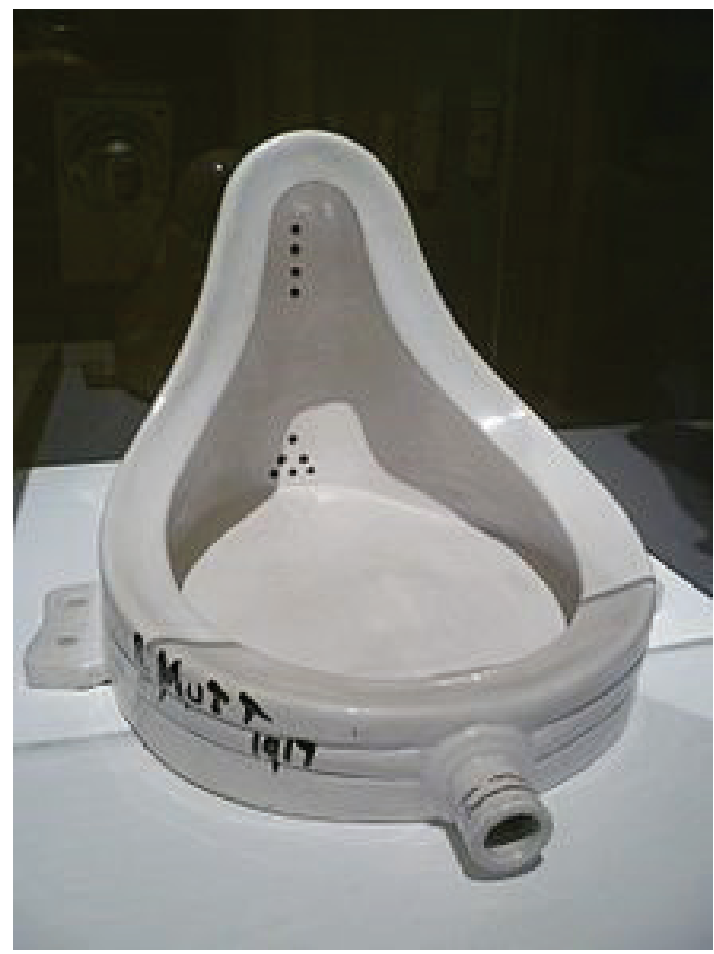

[Figura 3] Marcel Duchamp. A Fonte. 1917. Scottish National Gallery of Modern Art, Edimburgo, Escócia.

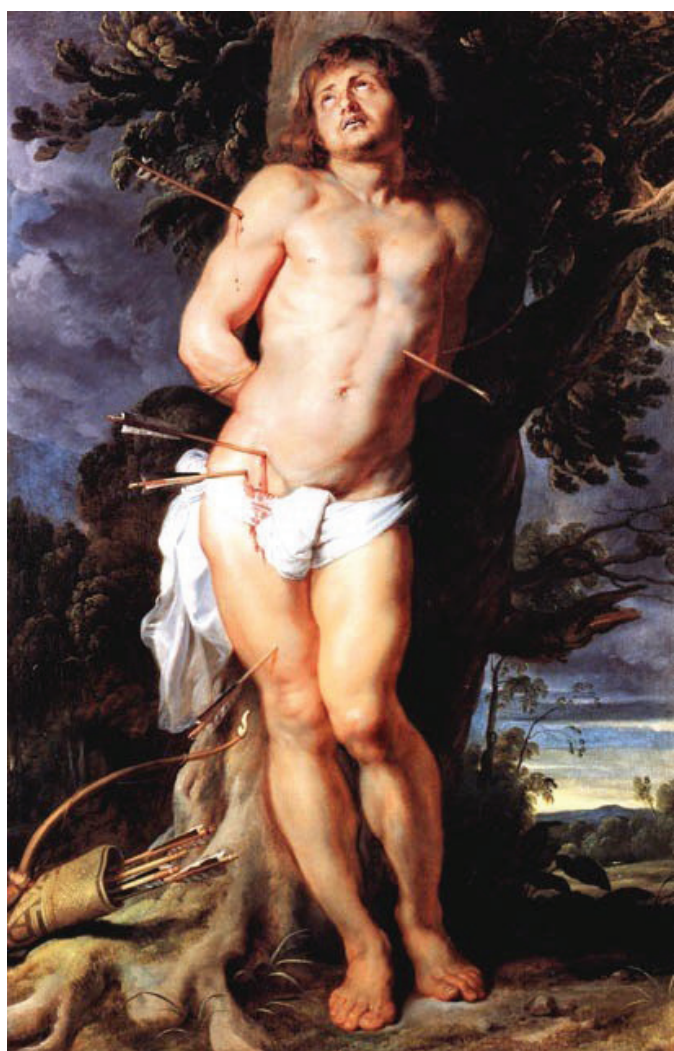

[Figura 2] Peter Paul Rubens. São Sebastião.

1614.

Berlin State Museums, Berlin, Alemanha.

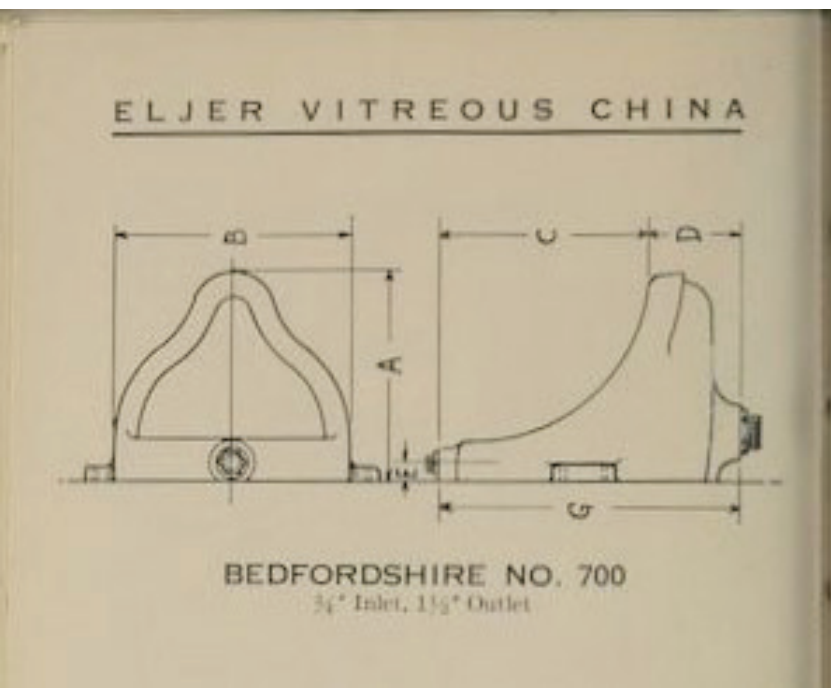

[Figura 4] Two-Fired Vitreous. China Catalogue, 1918. Bedfordshire No. 700. 
Não mais desfranze o cenho deste cruel doente.

Em tumba se transforma o seu florido leito,

E as aias, que acham todo príncipe perfeito,

Não sabem mais que traje erótico vestir

Para fazer este esqueleto enfim sorrir.

O sábio que ouro Ihe fabrica desconhece

Como extirpar-lhe ao ser a parte que apodrece,

E nem nos tais banhos de sangue dos romanos,

De que se lembram na velhice os soberanos,

Pôde dar vida a esta carcaça, onde, em filetes,

Em vez de sangue flui a verde água do Lestes.

Estas três instâncias acontecem devido uma relação objeto-afetiva, na qual três categorias psíquicas relacionam-se entre si e com a função dos objetos (das coisas): gosto estético, memória afetiva e o desejo-em-si. O gosto estético diz respeito a algo que nos punge ${ }^{7}$, aquele elemento subjetivo o qual não sabemos a priori porque nos atraiu, mas que nos afeta de modo a nos magnetizar (algo que nos chama atenção na obra: pode ser uma forma, um tema, uma personagem, uma cor, uma textura, um som, um discurso, uma rima, etc.); a memória afetiva é um 'depósito' de lembranças, imagens do inconsciente e sentimentos recalcados, que aparecem fragmentados, desordenados, e que, quando acessados pelo consciente, e ordenados pela linguagem, revelam nossas neuroses, psicoses, emoções de modo geral, e fatos que estavam 'esquecidos'; todavia, recriados por meio da afetividade, como queríamos que fosse, consubstanciados com nossa imaginação ('não foram de fato assim' $^{8}$; e o desejo é essa energia que nos impulsiona, e nela, que manifestam-se as percepções sobre as obras de arte.

[...] o gosto é um outro saber, que não pode dar razão de seu objeto, mas que goza dele; como uma forma especial de saber que goza do objeto belo e como uma forma especial de prazer que julga a beleza; como um lugar privilegiado no qual emerge a fratura do objeto

\footnotetext{
7 Pungir, vem de Punctum: "O conceito de Punctum, aqui, é emprestado de Roland Barthes, principalmente da obra A Câmara Clara (1984). É utilizado por Barthes para nomear um "detalhe" na foto que chama a atenção daquele que olha. Punctum, enquanto o que me punge, o que me toca, o que afeta. Claro que Barthes coloca esse conceito enquanto recepção de um olhar na foto, um detalhe expansivo e metonímico que leva o receptor da foto para estados outros, um estado-em-arte da foto." (FERRACINI- 2006, p. 3)

8 "[...] todas aquelas vivências ou impressões da vida cujo efeito de choque é interceptado pelo sistema percepção/consciência tornam-se conscientes. Logo, por estas vivências serem matérias da consciência, elas desaparecem instantaneamente, sem terem a chance de se incorporarem à "verdadeira" memória. Já aquelas experiências, excitações da vida que jamais se tornaram conscientes devido a ação do psiquismo, são remetidas ao inconsciente onde deixam nele rastros duráveis. Assim, para Benjamin, é a experiência que se assenta na "verdadeira" memória do homem, uma vez que a lógica benjaminiana obedece a seguinte ordem: quanto maior a atividade do fator choque nas impressões da vida, maior será a atuação do consciente em proteger-se contra estes estímulos; e quanto maior for o êxito desta operação, menos estas impressões serão incorporadas ao campo da experiência, consequentemente, corresponderão à vivência" (BENJAMIN, 2000, p.111). Importante destacar, que experiência envolve um modo subjetivo, pessoal, do sujeito interpretar vivências e, por vez, o que o cérebro registra, não são as coisas e experiências externas, mas o modo como compreendemos e criamos imagens mentais delas.
} 
do conhecimento em verdade e beleza, em conhecimento e gozo9.

Para entender como o gosto se manifesta nesta relação, é preciso compreender que, nascendo do desejo, o gosto é antes de mais nada, subjetivo. Mas, como funciona a subjetividade? Sartre ${ }^{10}$ diz que subjetividade é o julgamento de cada pessoa, como cada indivíduo julga (interpreta) um fenômeno, ou ainda, cria (na esfera da imaginação"1) determinado fenômeno. Assim, se subjetividade é a resposta formulada da associação da imaginação com a experiência, o gosto, sendo subjetivo, é resultante da imaginação com a experiência (o que eu gosto, gosto porque algo naquilo que gosto me punge, e porque algo me diz, numa vivência com a coisa, que ela é prazerosa). Gosto é uma associação daquilo que aciona satisfação por meio dos sentidos, com aquilo que se torna objeto do nosso desejo. Porém, por se manifestar por meio do prazer, o gosto pode ser mutável, diria, pois, transitório.

O gosto julga o mundo em sua aparência e temporalidade; seu interesse pelo mundo é puramente "desinteressado", o que significa que nem os interesses vitais do indivíduo, nem os interesses morais do eu se acham aqui implicados. Para os juízos do gosto, o mundo é objeto primário, e não o homem, nem a vida do homem, nem seu eu. ${ }^{12}$

Isto nos faz pensar no gosto coletivo nas artes. Aquilo que nós, socialmente, definimos como arte. Como julgamos o que no mundo é arte? O que faz uma pintura, uma escultura, um ballet, uma música se tornarem obras de artes e que faz com que outra pintura, escultura, ballet ou música não sejam obras de arte (a exemplo, a distinção que se faz no cinema entre filme-arte e filme comercial). Inúmeros são os elementos que distinguem o objeto-arte do produto comercial. Isto demandaria um outro artigo ou mesmo uma tese. O que nos importa, neste artigo, é a concepção de o conteúdo é tão imponente na formulação do gosto que talvez, ele defina conceitos de belo e feio (que dariam outro artigo ou tese), num julgamento que infere que a belo é aquilo que agrada, que tem padrões, normas, conceitos que refletem alguma importância cultural, histórica, social. Por isso, o que se define como belo está sempre em mudança. E, assim o gosto.

O exercício do gosto segue aquelas secretas afinidades eletivas, ocultos parentescos, instintivas cogenialidades que alimentam, ou melhor, regulam toda a vida espiritual e ligam entre si, de modo sempre surpreendente e maravilhoso, as obras de diversos campos, ou

\footnotetext{
9 OLIVEIRA, apud AGAMBEN, Giorgio. Gosto. São Paulo: Autêntica, 2017, p. 82.

10 SARTRE, Jean-Paul. O que é subjetividade?. Rio de Janeiro: Nova Fronteira, 2015.

11 Imaginação, para Flusser (2002, p.7) "é a capacidade de fazer e decifrar imagens".

12 ARENDT, Hannah. A crise da cultura: sua importância social e política. In: Entre o passado e o futuro. São Paulo: Perspectiva, 2003, p.277.
} 
artístico ou filosófico ou prático ou religioso ou político, mas de uma mesma época, com vínculos ocultos, mas nem por isso menos reais ${ }^{13}$

Talvez, por isso, temos essa urgência de mudanças de sentidos artísticos (ainda que, historicamente, criações do passado, são contemporaneamente assumidas como obras de arte -'tem importância histórica'): numa época de predominância religiosa, temos o Renascimento e o Barroco pungentes, noutra época de uma Belle Époque, surge o Impressionismo, num período de guerra, encontramos artistas confortando na psicanálise, concebendo o Movimento Surrealista, e assim por diante. Mas são sempre estéticas e conteúdos definidos no senso comum dos seres humanos.

[Juízo estético e política] pertencem à mesma categoria porque não é o conhecimento ou a verdade que está em jogo, mas sim o julgamento e a decisão, a judiciosa troca de opiniões sobre a esfera da vida pública e do mundo comum e a decisão quanto ao modo de ação a adotar nela além do modo como deverá parecer doravante e que espécie de coisas nele hão de surgir ${ }^{14}$.

Gosto... uma questão de subjetividade

O gosto é, então a faculdade de julgar a priori a comunicabilidade de sentimentos que se ligam a dada representação [...] se pudéssemos supor que a mera comunicabilidade geral de um sentimento traz consigo, em si mesma, um interesse para nós [...] deveríamos ser capazes de explicar porque o sentimento, no juízo do gosto, vem a ser imputado em cada um, por assim dizer como um dever ${ }^{15}$.

Kant vai dizer que existem três tipos de prazer, o do agradável, que é derivado do contato material com o mundo exterior; o do bom, moral, absoluto ou relativo; e o da beleza, que não se baseia nas sensaç̃es, é considerado um prazer puro. Quando gosto precisa associar forma ao conteúdo, o prazer, nestes domínios, definir o que agrada (satisfaz os sentidos), o que é bom (que tem princípios éticos), e que é belo (contemplação pura, livre de paradigmas), confere uma necessidade de continência, pois é o conceito acordado que irá permitir que o gosto não transite somente na esfera do sensorial, portanto do prazer, mas que de contiguidade no desejo. Quando deparamos

\footnotetext{
PAREYSON, Luigi. Os Problemas da Estética (3 ${ }^{\mathrm{a}}$ ed.). São Paulo: Martins Fontes, 1997. p.35

15 KANT, Immanuel. Crítica da faculdade de julgar. Capítulo 40: do gosto como uma espécie de sensus communis. Petrópolis: Editora Vozes, 2016. n.p.
} 
com a dúvida sobre o que gostamos numa obra de arte: se é a forma (estética figurativa) ou o conteúdo, reconhecemos que conhecimento e prazer não dissociam. Por mais que o gosto seja apenas estético, valores (seja uma memória afetiva, uma sensação ou um aprendizado sócio educacional) ligados ao conteúdo conduzem nosso modo de ver, ouvir, tatear etc. Aquém do instinto e da natureza biológica, nós aprendemos a ver, ouvir, tatear etc., por meio de aprendizados culturais (família, escola, sociedade etc.).

Forma e conteúdo são vistos em sua inseparabilidade: o conteúdo nasce como tal no próprio ato em que nasce a forma, e a forma não é mais que a expressão acabada do conteúdo [...] "a inseparabilidade da forma e conteúdo é afirmada do ponto de vista do conteúdo: fazer arte significa 'formar' conteúdos espirituais, dar uma 'configuração' à espiritualidade ${ }^{16}$

Conhecimento e prazer caminham juntos na construção de um discurso sobre o que é arte, tal qual sobre como se formula a propriedade do gosto nos seres humanos. O gosto é uma faculdade a partir da qual proferimos juízos estéticos e sentido sobre a obra de arte. Transferimos a um 'objeto' (pintura, escultura, música, etc.) uma história, uma narrativa, valores políticos, sociais, culturais, institucionais. A relação de gosto e arte, no campo do desejo, transcorre de um sentimento de prazer cuja finalidade subjetiva é pensada antes de ser sentida, e, sendo transitório, faz com que o juízo de sentidos estéticos não esteja ligado à faculdade-de-conhecimento. Ao pertencer e deixar com que a satisfação (o clímax do prazer) domine a estética, é preciso, adentrar no abismo do conhecimento, dominar o prazer, para viver, então, o desejo, e assim julgar o prazer por meio da crítica (entendimento e razão).

No campo da estética, o gosto transmuta pela atualização e nossos sentidos, é uma fusão entre o biológico e o aprendizado (aprendemos a conhecer nosso corpo e ele passa a desfrutar mais precisamente dos sentidos de maneira que outrora não desfrutávamos). No campo do conhecimento, o gosto se comporta como uma esponja, absorve as moléculas dos domínios das ciências; depois funciona como uma peneira que filtra esses signos (mas não de uma maneira precisa, pois deixa transpassar do inconsciente, por exemplo, a memória afetiva) e por fim tenta ordená-los para dar um sentido a coisa observada. Ainda que sendo subjetiva as respostas a essa dúvida incipiente, arrisco, pois, uma pequena reflexão: Uma vez que conteúdo e forma caminham juntos, o gosto é, por senão, uma predileção pelos signos que satisfazem nossos desejos.

16 PAREYSON, Luigi. Os Problemas da Estética ( $3^{\mathrm{a}}$ ed.). São Paulo: Martins Fontes, 1997. p.55 


\section{Referências Bibliográficas}

ACAMBEN, Giorgio. Costo. São Paulo: Autêntica, 2017.

ARENDT, Hannah. A crise da cultura: sua importância social e política. In: Entre o passado e o futuro. São Paulo: Perspectiva, 2003.

BATAILLE, Georges. O erotismo. Porto Alegre: L\&PM, Porto Alegre, 1987.

BAUDELAIRE, Charles, As flores do mal, poema LXXVII, tradução: Ivan Junqueira, Editora Nova Fronteira, 2018

BENJAMIN, Walter. Obras escolhidas. Charles Baudelaire um lírico no auge do capitalismo. v.3. (segunda reimpressão). São Paulo: Brasiliense, 2000.

FERRACINI, Renato. Codificar para recriar: a Busca do Punctum. Florianópolis: Urdimento, v. 1, n. 1, p.39-47, 2006.

FLUSSER, Vilém. Filosofia da caixa preta: ensaios para uma futura filosofia da fotografia. Rio de Janeiro: Ed. Relume Dumará, 2002.

KANT, Immanuel. Crítica da faculdade de julgar. Capítulo 40: do gosto como uma espécie de sensus communis. Petrópolis: Editora Vozes, 2016.

LACAN, Jacques. (1956-1957). O Seminário livro 4, A relação de objeto. Rio de Janeiro: Jorge Zahar. 1995

LÖBACH, Bernd. Design industrial: bases para a configuração dos produtos industriais. São Paulo: Edgard Blücher, 2001.

PAREYSON, Luigi. Os Problemas da Estética ( $3^{\mathrm{a}}$ ed.). São Paulo: Martins Fontes, 1997.

SARTRE, Jean-Paul. O que é subjetividade?. Rio de Janeiro: Nova Fronteira, 2015. 